\title{
ANALISIS PERFORMANCE KINCIR ANGIN SUMBU VERTIKAL TIGA SUDUT DENGAN KELENGKUNGAN 90
}

\author{
Peri Pitriadi ${ }^{1}$, Reza Bachmid ${ }^{2}$ dan I Made Susanto ${ }^{3}$ \\ ${ }^{1,2,3)}$ Politeknik Batulicin' Kalimantan Selatann \\ Email: ")peripitriadisst@gmail.com ${ }^{1}$
}

\begin{abstract}
Wind energy potential in indonesia based on BMKG data quite high where speed rate of wind is 10,28 $\mathrm{m} / \mathrm{s}$ because of that its needed wind energy converter which suitable with that wind rate profil. In wind utilization as source of energy, especially as motion energy, equiptment be required which function as catcher of energy from wind as we know as windmill. This research intend to find and explain the best performance from windmill with vertically axis three blade with curvature 90. The development of pinwheel which do by change the blade savonius windmill become curvature 90 and designed with aspect ratio $=2,8$, overlap $=0,2$ cross-sectional area of windmill is $0,07 \mathrm{~m}^{2}$. Research carried out with wind speed from 1,6 m/s till 4,2 m/s. In reasearch measurement do by wheel shaft rotation, current and output voltage DC generator for each different wind speed. Based on the result of the reasearch, windmill vertically axis three blade able to extracted wind power become wind generator (output) with rate $30 \%$. The best performance from windmill vertically axis three blade with curvature 90 have highest coefficient power value at wind speed $=2,2 \mathrm{~m} / \mathrm{s}$ that is 0,4 .
\end{abstract}

Keywords: Wind Power, windmill type 90 blade, three blade, coefficient power.

\begin{abstract}
ABSTRAK
Potensi energi angin di Indonesia khususnya di Kalimantan Selatan berdasarkan data BMKG cukup tinggi, dengan kecepatan angin rata-rata 10,28 m/s oleh karena itu diperlukan sistem konversi energi angin yang sesuai dengan profil kecepatan angin tersebut. Dalam pemanfaatan angin sebagai sumber energi, terutama sebagai energi gerak, dibutuhkan alat yang berfungsi sebagai penangkap energi dari angin yang dikenal sebagai kincir angin. Penelitian ini bertujuan untuk menemukan dan menjelaskan kinerja terbaik dari kincir angin sumbu vertikal tiga sudu dengan kelengkungan $90^{\circ}$. Pengembangan kincir yang dilakukan yaitu merubah bentuk sudu kincir angin savonius menjadi kelengkungan $90^{\circ}$ dan dirancang dengan aspek rasio $=2,8$, overlap $=0,2$ luas penampang kincir angin adalah 0,07 $\mathrm{m}^{2}$. Penelitian dilakukan dengan kecepatan angin dari 1,6 m/s sampai 4,2 m/s. Dalam penelitian dilakukan pengukuran terhadap putaran poros kincir, arus dan tegangan keluaran generator DC untuk setiap kecepatan angin yang berbeda. Berdasarkan hasil penelitian, kincir angin sumbu vertikal tiga sudu mampu mengekstraksi daya angin menjadi daya generator (output) rata-rata $30 \%$.Kinerja terbaik dari kincir angin sumbu vertikal tiga sudu dengan kelengkungan $90^{\circ}$ memiliki nilai koefisien power tertinggi pada kecepatan angin = $=2,2 \mathrm{~m} / \mathrm{s}$ yaitu 0,4 .
\end{abstract}

Kata kunci: Energi angin, Kincir angin tipe sudu 90 , Tiga Sudu, Koefisien power

\section{PENDAHULUAN}

Salah satu sumber energi terbarukan adalah energi angin. Energi angin merupakan salah satu sumber daya yang berlimpah, ramah lingkungan dan bersifat renewable, untuk itu sangat berpotensi untuk dikembangkan (Sumiati, 2012). Energi yang dapat dimanfaatkan dari angin adalah energi kinetik yang diubah menjadi energi mekanik atau gerak. Dalam pemanfaatan angin sebagai sumber energi terutama sebagai energi gerak, dibutuhkan alat yang berfungsi sebagai penangkap energi dari angin yang dikenal sebagai kincir angin (Sarjono dkk., 2011).

Potensi energi angin di Indonesia yaitu rata-rata kecepatan angin di Indonesia berkisar antara 3-6 m/s. Oleh karena itu diperlukan sistem konversi energi angin yang sesuai dengan profil kecepatan angin di Indonesia (Fitranda \& Siregar, 2014). 
Untuk memanfaatkan energi angin tersebut digunakan kincir angin yang saat ini banyak digunakan untuk membangkitkan tenaga listrik. Prinsip dasar kerja dari kincir angin untuk pembangkitan listrik adalah mengubah energi mekanik dari angin menjadi energi putar pada kincir, lalu putaran kincir digunakan untuk memutar generator yang akan menghasilkan listrik. Salah satu jenis kincir angin adalah kincir angin sumbu vertikal memiliki poros atau sumbu rotor utama yang disusun tegak lurus (Bahri dkk., 2014).

Kincir angin sumbu vertikal mampu memanfaatkan angin dari berbagai arah serta memiliki kemampuan self-starting yang bagus, sehingga hanya membutuhkan angin dengan kecepatan rendah untuk dapat memutar rotor dari turbin angin ini. Selain itu, torsi yang dihasilkan kincir angin jenis sumbu vertikal relatif tinggi. Peningkatan koefisien daya tergantung pada desain dari kincir angin Savonius yang dimodifikasi (Marnoto, 2011).

Pada dasarnya, banyak faktor yang dapat mempengaruhi performansi kincir angin savonius. Namun dalam penelitian ini, variabel yang diteliti yaitu pengaruh variasi profil kurva blade terhadap daya yang dihasilkan kincir angin savonius untuk angin berkecepatan rendah. Diduga profil kurva blade dengan panjang sumbu lebih besar akan menghasilkan daya yang lebih tinggi dibanding profil kurva blade dengan panjang sumbu lebih kecil (Pradana dkk., 2013).

Dalam beberapa penelitian terdahulu tentang rancang bangun kincir angin vertikal jenis savonius tipe $U$ dengan variasi jumlah sudu 2, 3 dan 4 diperoleh bahwa Kincir konvensional 2 sudu dengan adanya circular shield memperlihatkan performa yang lebih baik dibandingkan dengan kincir angin lebih dari 2 sudu. Circular shiled mampu menambah dan meningkatkan torsi awal untuk memulai putaran awal kincir dan mampu menambah putaran kincir secara signifikan. Nilai koefisien power meningkat cukup tinggi rata-rata peningkatannya sebesar 87\% (Haqqqi dkk., 2013). Penelitian ini difokuskan pada kincir angin sumbu vertikal dengan tujuan untuk mendapatkan desain dari kincir angin sumbu vertikal yang dapat menghasilkan efisiensi pada profil kecepatan angin di Indonesia yang rendah dan fluktuatif.

\section{METODE PENELITIAN}

Jenis penelitian yang dilakukan adalah penelitian eksperimen, yaitu dengan melakukan pengamatan atau pengukuran terhadap variabel yang ditentukan untuk mengetahui kemampuan kerja kincir angin sumbu vertikal tipe sudu 90 -.Kincir angin sumbu vertikal tipe sudu $90^{\circ}$ merupakan pengembangan dari kincir angin savonius konvensional yang berdasarkan hasil penelitian terdahulu memiliki koefisien power maksimal sekitar 0,3. Pengembangan dilakukan pada bentuk sudu yaitu dari bentuk sudu kincir savonius menjadi kelengkungan $90^{\circ}$. Selain dari pengembangan bentuk sudu, kincir angin sumbu vertikal tipe sudu $90^{\circ}$ dirancang dengan aspek rasio $=$ 2,8 dan overlap $=0,2$ (Sargolzaei, 2007). Luas penampang kincir angin yang di rancang adalah $0,07 \mathrm{~m}^{2}$. Gambar model penelitian ada di halaman belakang.

Pengujian karakteristik kincir ini terdiri dari pengukuran kecepatan angin dari sumber angin, dan pengukuran putaran kincir, tegangan dan arus keluaran generator DC pada masing-masing variasi kecepatan angin.

Kecepatan angin diukur dengan menggunakan anemometer. Pengambilan data ini dilakukan dengan 
variasi kecepatan angin dari $1,6 \mathrm{~m} / \mathrm{s}$ sampai 4,2 m/s. Pengukuran ini diulang beberapa kali dan diambil nilai yang paling banyak muncul. Ketika pengambilan data, anemometer disangga agar posisinya konstan terhadap sumber angin.

Pengukuran kecepatan angin dilakukan dengan tidak menyertakan kincir, hal ini bertujuan untuk mengetahui kecepatan awal angin sebelum menumbuk kincir. Apabila pengukuran kecepatan angin dilakukan bersamaan dengan pengukuran kecepatan putar kincir, hasil pengukuran akan sedikit berbeda karena putaran kincir akan mempengaruhi nilai kecepatan angin yang diukur oleh anemometer.

Pengukuran selanjutnya adalah pengukuran putaran kincir terhadap variasi kecepatan angin. Pengukuran dilakukan dengan menggunakan tachometer. Alat ini menggunakan sumber cahaya yang dapat disinkronisasi dengan setiap putaran benda. Sebelum pengukuran dilakukan, kincir diberi tanda terlebih dahulu, misalnya dengan menempelkan kertas putih pada poros kincir untuk mempermudah pembacaan nilai putaran kincir. Pengukuran tegangan dan arus keluaran generator DC dilakukan dengan menggunakan multimeter digital.

Perhitungan untuk menentukan kinerja dari kincir angin sumbu vertikal dapat dilakukan dengan menggunakan persamaan berikut :

\section{a. Daya angin}

Daya yang dihasilkan dari konversi energi angin oleh kincir angin sebanding dengan pangkat tiga kecepatan angin. Adapun daya yang dihasilkan kincir angin dapat diperoleh dengan menggunakan persamaan berikut ini:

$$
P_{A}=1 / 2 \quad \rho \quad A \quad v^{3}
$$

Keterangan :

$\mathrm{P}_{\mathrm{A}}=$ Daya angin (watt)

$\rho=$ Densitas udara $\left(1,1543 \mathrm{~kg} / \mathrm{m}^{3}\right)$

$A=$ Luas penampang $\operatorname{kincir}\left(\mathrm{m}^{2}\right)$ $\mathrm{v}=$ Kecepatan angin $(\mathrm{m} / \mathrm{s})$

\section{b. Daya Generator}

Generator merupakan sebuah perangkat motor listrik yang mengubah energi mekanis menjadi energi listrik. Shaft dari kincir angin akan dikoneksikan dengan generator DC dan untuk menghitung daya yang dihasilkan maka digunakan persamaan:

$$
P_{\text {generator }}=V x I
$$

(2)

Keterangan:

Pgenerator = Daya generator

listrik (Watt)

$\mathrm{V} \quad=$ Tegangan generator litrik

(Volt)

I = Arus listrik (Ampere)

c. Brake Horse Power (BHP)

$B H P=P_{\text {generator }} / \eta_{\text {generator }}$

(3)

Keterangan:

BHP = Brake Horse Power

(watt)

Pgenerator $=$ Daya generator

listrik (watt)

$\eta$ generator $=$ Efisiensi generator listrik (82\%)

d. Torsi (T)

$$
T=P_{\text {generator }} /(2 \pi n / 60)
$$

(4)

Keterangan:

$$
\begin{aligned}
& \mathrm{T}=\text { Torsi }(\mathrm{Nm}) \\
& \mathrm{n}=\text { Putaran Poros }(\mathrm{rpm})
\end{aligned}
$$

\section{e. Tip Speed Ratio (TSR)}

Tip speed ratio adalah perbandingan antara kecepatan ujung vane dengan kecepatan angin yang melewatinya. TSR merupakan besaran tak berdimensi yang 
menyatakan hubungan antara kecepatan angin dengan rata-rata putaran dari kincir angin. Rasio kecepatan ujung rotor memiliki nilai nominal yang berubah-ubah terhadap perubahan kecepatan angin. Turbin angin tipe lift memiliki TSR yang lebih besar dibanding dengan turbin angin tipe drag. Adapun persamaan untuk memperoleh harga besaran ini adalah sebagai berikut:

$\lambda=\omega \cdot R / v$

(5)

Keterangan :

$\lambda=$ tip speed ratio

$\omega=$ kecepatan sudut turbin ( $\mathrm{rad} / \mathrm{s})$

$\mathrm{R}=$ jari-jari turbin $(\mathrm{m})$

$\mathrm{v}=$ kecepatan angin $(\mathrm{m} / \mathrm{s})$

\section{f. Koefisien daya (Cp)}

Seperti diketahui ternyata energi kinetik yang dimiliki angin tidak seluruhnya dapat dikonversikan menjadi gaya mekanik (dengan adanya komponen gaya seret yang mengurangi komponen gaya angkat). Dengan demikian terjadi kerugian daya . perbandingan antara daya yang dihasilkan dengan daya angin disebut koefisien daya (Cp). Bila kecepatan angin bertambah maka daya dan torsi bertambah. Untuk maksud penyederhanaan, daya, torsi, dan putaran dikelompokkan dalam relasi berikut :

$$
C p=B H P / P_{\text {angin }}
$$

Tabel pengamatan dapat dilihat dihalaman belakang .

\section{HASIL DAN PEMBAHASAN}

Setelah melakukan pengambilan dan menganalisis data maka dapat dilihat seberapa besar kinerja kincir angin sumbu vertikal tipe sudu $90^{\circ}$ dengan tiga sudu. Hasil data Pengamatan dapat dilihat pada Tabel 2 Hasil Pengamatan dihalaman belakang. Gambar 1 menunjukan grafik hubungan daya angin dengan generator

\section{a. Pengaruh daya angin ( $\left.P_{\text {angin }}\right)$ terhadap daya generator $\left(P_{\text {generator}}\right)$}

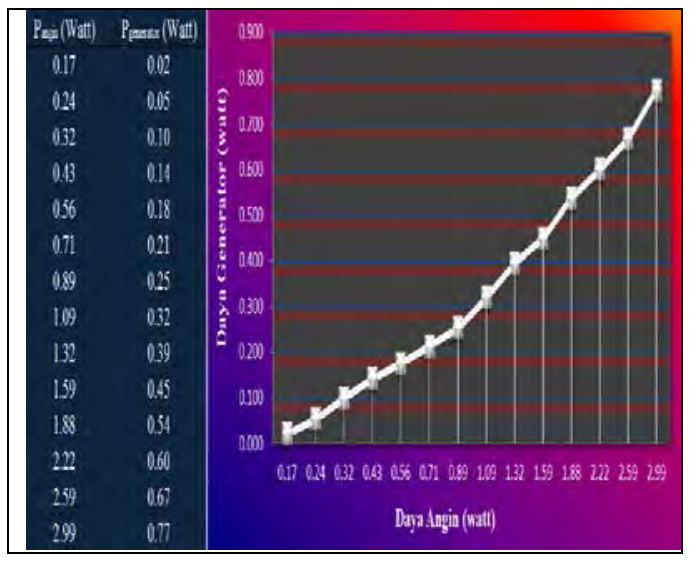

Perbandingan daya angin $\left(P_{\text {angin }}\right)$ dan daya generator $\left(P_{\text {generator }}\right)$ yang merupakan keluaran dari kincir angin memperlihatkan $\mathrm{P}_{\text {generator semakin naik }}$ seiring dengan kenaikan $P_{\text {angin }}$.Dari grafik perbandingan dapat di lihat bahwa kincir angin dengan tiga sudu mampu mengekstraksi daya angin menjadi daya generator (output) rata-rata 30\% . Untuk daya angin tertinggi pada pengujian $\mathrm{v}=$ $4,2 \mathrm{~m} / \mathrm{s}$ yaitu 2,99 watt daya output generator 0,77 watt, yang artinya kincir angin hanya mampu mengekstraksi daya angin menjadi daya generator sebesar 26\% dan untuk daya angin terendah pada pengujian $\mathrm{v}=1,6 \mathrm{~m} / \mathrm{s}$ yaitu 0,17 watt daya output generator 0,02 watt, yang artinya kincir angin hanya mampu mengekstraksi daya angin menjadi daya generator sebesar 13\%. Kemampuan kincir untuk mengekstraksi daya angin menjadi daya generator yang paling baik pada kecepatan angin $2,2 \mathrm{~m} / \mathrm{s}$ dimana daya angin $=0,43$ watt dan daya keluaran generator 0,14 watt yang artinya kemampuan kincir untuk mengekstraksi daya angin menjadi daya generator sebesar 33\%. 


\section{b. Pengaruh kecepatan angin (V) terhadap putaran kincir (n)}

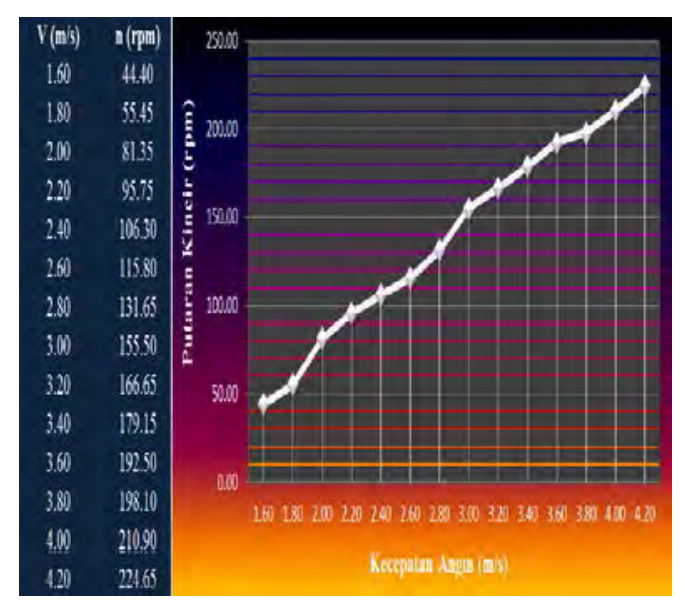

Gambar 2. Grafik hubungan antara kecepata angin dengan putaran kincir Pengaruh kecepatan angin (v) terhadap putaran kincir (n) memperlihatkan bahwa semakin tinggi kecepatan angin maka semakin tinggi pula putaran kincir - Grafik perbandingan diatas dapat di lihat bahwa kincir angin dengan tiga sudu pada kecepatan angin terendah 1,6 $\mathrm{m} / \mathrm{s}$ mampu menghasilkan putaran sebesar 44,40 rpm dan untuk kecepatan angin tertinggi pada pengujian yaitu 4,2 $\mathrm{m} / \mathrm{s}$ dapat menghasilkan putaran kincir 224,65 rpm.

\section{c. Hubungan antara tip speed ratio(TSR) dengan koefisien daya (Cp)}

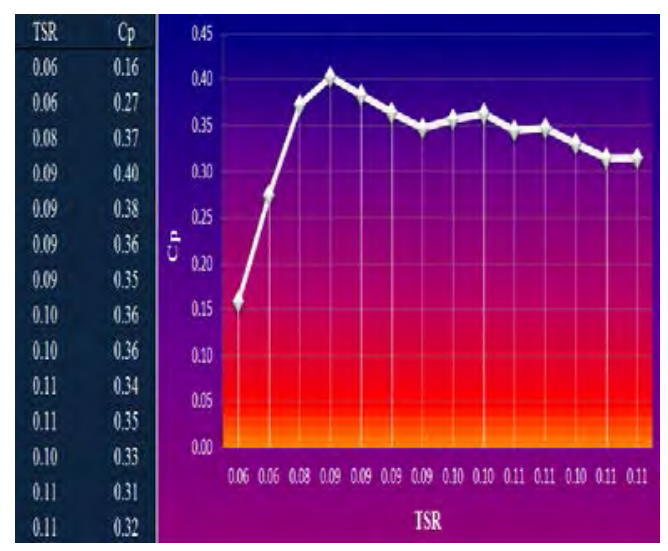

Gambar 3. Grafik hubungan antara TSR dengan Cp
Grafik perbandingan TSR dengan Cp menunjukkan bahwa kincir angin dengan tiga sudu memiliki nilai koefisien power yang jauh lebih pada TSR =0,09 yaitu sekitar 0,4 dan koefisien power terendah pada TSR $=0,06$ yaitu 0,16 .

\section{d. Pengaruh kecepatan angin (V) koefisien daya (Cp)}

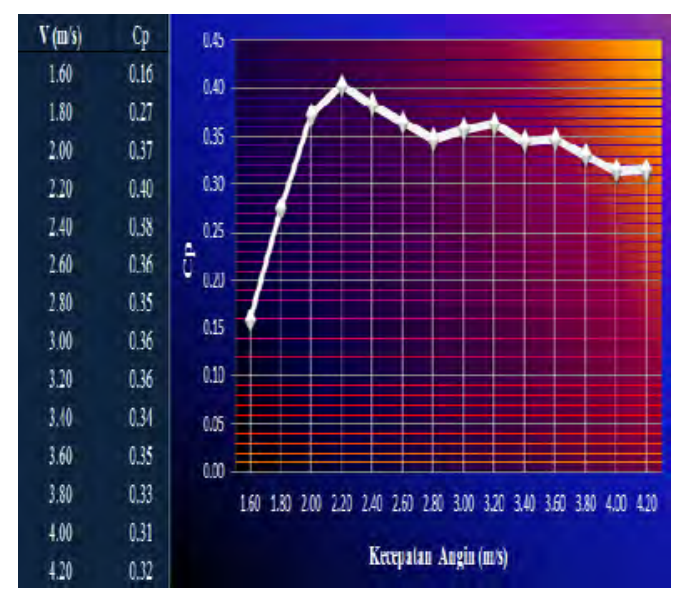

Gambar 4. Grafik hubungan antara kecepatan angin dengan $\mathrm{Cp}$

Grafik hubungan antara kecepatan angin dengan koefisien power menunjukkan bahwa kincir angin dengan tiga sudu memiliki nilai koefisien power yang jauh lebih pada kecepatan angin $=2,2$ yaitu sekitar 0,4 dan koefisien power terendah pada kecepatan angin $=1,6$ yaitu sekitar 0,16.

\section{KESIMPULAN}

Pengembangan kincir tiga sudu yang dilakukan dengan cara memodifikasi sudu kincir savonius dari derajat kelengkungan $\quad 180^{\circ}$ menjadi kelengkungan $90^{\circ}$. dengan aspek rasio $=$ 2,8 overlap $=0,2$ dan luas penampang kincir angin adalah $0,07 \mathrm{~m}^{2}$, hasilnya mampu mengekstraksi daya angin menjadi daya generator (output) ratarata 30\% . Dengan nilai koefisien power pada kecepatan angin 2,2 m/s yaitu sekitar $0,4 \quad 40 \%$ dengan dan koefisien power $16 \%$ terendah pada kecepatan angin $1,6 \mathrm{~m} / \mathrm{s}$.- 


\section{DAFTAR PUSTAKA}

[1.] Bahri S. dkk. (2014). Unjuk kerja turbin angin savonius dua tingkat empat sudu lengkung L. Jurnal Seminar Tahunan Teknik Mesin, 6(1): 978-602.

[2.] Budi F. dkk.(2011). Kincir angin poros vertikal sebagai alternatif penggerak pompa irigasi perkebunan di desa karyamukti. Jurnal Teknik Mesin Politeknik Negri Bandung, 6(3): 1-6.

[3.] Fitranda R. \& Siregar I. (2014). Karakteristik turbin angin savonius 2 dan 3 blade dengan menggunakan bantuan guide vane. Jurnal Teknik Mesin, 7(2): 125131.

[4.] Haqqqi M. dkk.(2013). Rancang bangun turbin angin vertikal jenis savonius dengan variasi jumlah blade terintegrasi circular shield untuk memperoleh daya maksimum. Jurnal Teknik Pomits, 6(1): 1-6.

[5.] Marnoto. (2011). Peningkatan efisiensi kincir angin poros vertikal melalui sistem melalui buka tutup sirip 3 sudu. Jurnal Teknik Mesin, 8(2):122-129.

[6.] Pradana A. dkk.(2013). Rancang bangun turbin angin vertikal jenis savonius dengan variasi profil kurva blade untuk memperoleh daya maksimum. Jurnal Teknik POMITS, 6(1): 1-6.

[7.] Sarjono B. dkk. (2011). Pengaruh perubahan jumlah blade spiral 5 \& 3 terhadap performa kincir angin savonius dengan bentuk blade spiral. Majalah Ilmiah STTR Cepu, $\quad$ 7(1): 1693 - 7066.

[8.] Sargolzaei. (2007). Prediction of the power ratio and torque in wind turbine Savonius rotors using artificial neural networks. Proceedings of the WSEAS International Conference on
Renewable Energy Sources, 6(6): 7-12.

[9.] Setiawan A. dkk.(2012). Pengaruh jarak celah sudu terhadap unjuk kerja turbin angin poros vertikal savonius. Teknik Mesin Fakultas Teknik Universitas Brawijaya, 8(4): 1-8.

[10.] Sumiati. (2012). Pengujian turbin angin savonius tipe u tiga sudu di lokasi pantai air tawar padang. Jurnal Teknik Mesin, 7(1): 18298958 


\section{LAMPIRAN}

Tabel 1. Pengambilan data kincir angin sumbu vertikal tipe sudu $90^{\circ}$ dengan tiga sudu

\begin{tabular}{|c|c|c|c|c|}
\hline No & $\begin{array}{c}\text { Kecepatan angin } \\
(\mathbf{m} / \mathbf{s})\end{array}$ & $\begin{array}{c}\text { Putaran } \\
(\mathbf{r p m})\end{array}$ & $\begin{array}{c}\text { Tegangan } \\
(\text { Volt })\end{array}$ & $\begin{array}{c}\text { Arus } \\
(\text { Ampere })\end{array}$ \\
\hline 1 & 1.60 & 44.40 & 0.35 & 0.06 \\
\hline 2 & 1.80 & 55.45 & 0.55 & 0.10 \\
\hline 3 & 2.00 & 81.35 & 0.75 & 0.13 \\
\hline 4 & 2.20 & 95.75 & 0.90 & 0.16 \\
\hline 5 & 2.40 & 106.30 & 1.00 & 0.18 \\
\hline 6 & 2.60 & 115.80 & 1.10 & 0.19 \\
\hline 7 & 2.80 & 131.65 & 1.20 & 0.21 \\
\hline 8 & 3.00 & 155.50 & 1.35 & 0.24 \\
\hline 9 & 3.20 & 166.65 & 1.50 & 0.26 \\
\hline 10 & 3.40 & 179.15 & 1.60 & 0.28 \\
\hline 11 & 3.60 & 192.50 & 1.75 & 0.31 \\
\hline 12 & 3.80 & 198.10 & 1.85 & 0.32 \\
\hline 13 & 4.00 & 210.90 & 1.95 & 0.34 \\
\hline 14 & 4.20 & 224.65 & 2.10 & 0.37 \\
\hline
\end{tabular}

Tabel 2. Hasil analisis data kincir angin sumbu vertikal tipe sudu $90^{\circ}$ dengan tiga sudu

\begin{tabular}{|c|c|c|c|c|c|c|}
\hline No & $\begin{array}{c}\text { Daya Angin } \\
\text { ( watt) }\end{array}$ & $\begin{array}{c}\text { Daya Generator } \\
\text { (watt) }\end{array}$ & BHP & $\begin{array}{c}\text { Torsi } \\
\text { (Nm) }\end{array}$ & Tip Speed Ratio & CP \\
\hline 1 & 0.17 & 0.021 & 0.026 & 0.005 & 0.06 & 0.16 \\
\hline 2 & 0.24 & 0.053 & 0.065 & 0.009 & 0.06 & 0.27 \\
\hline 3 & 0.32 & 0.099 & 0.120 & 0.012 & 0.08 & 0.37 \\
\hline 4 & 0.43 & 0.142 & 0.173 & 0.014 & 0.09 & 0.40 \\
\hline 5 & 0.56 & 0.175 & 0.214 & 0.016 & 0.09 & 0.38 \\
\hline 6 & 0.71 & 0.212 & 0.259 & 0.018 & 0.09 & 0.36 \\
\hline 7 & 0.89 & 0.253 & 0.308 & 0.018 & 0.09 & 0.35 \\
\hline 8 & 1.09 & 0.320 & 0.390 & 0.020 & 0.10 & 0.36 \\
\hline 9 & 1.31 & 0.395 & 0.481 & 0.023 & 0.10 & 0.36 \\
\hline 10 & 1.59 & 0.449 & 0.548 & 0.024 & 0.11 & 0.34 \\
\hline 11 & 1.88 & 0.537 & 0.655 & 0.027 & 0.11 & 0.35 \\
\hline 12 & 2.22 & 0.600 & 0.732 & 0.029 & 0.10 & 0.33 \\
\hline 13 & 2.59 & 0.667 & 0.814 & 0.030 & 0.11 & 0.31 \\
\hline 14 & 2.99 & 0.774 & 0.944 & 0.033 & 0.11 & 0.32 \\
\hline
\end{tabular}


Peri Pitriadi, Reza Bachmid dan I Made Susanto, Analisis Performance Kincir... 